\title{
Insights from olivine oxygen isotope compositions into the mantle sources of picrites from the Karoo LIP
}

\author{
KiERAN A. ILES* ${ }^{1}$, ARto V. LUTTINEN ${ }^{1}$, MARTIN J. \\ WHITEHOUSE $^{2}$ \\ ${ }^{1}$ Finnish Museum of Natural History, Univeristy of Helsinki, \\ P.O. Box 64, 00014 Helsinki, Finland (*correspondence: \\ kieran.iles@helsinki.fi) \\ ${ }^{2}$ Department of Geosciences, Swedish Museum of Natural \\ History, P.O. Box 50 077, 10405 Stockholm, Sweden
}

Continental flood basalts in the Karoo large igneous province (LIP) have been divided into low- $\mathrm{Ti}$ and high-Ti groups, with contributions from recycled crust to the mantle source region inferred for high-Ti picrites. Picrites from the Luenha river, Mozambique, represent a low-Ti end-member of the compositional diversity. Several geochemical characteristics (including $\varepsilon \mathrm{Nd}_{180 \mathrm{Ma}}-2.0$ to +1.4 and strongly positive $\Delta \mathrm{Nb}$ ) of the Luenha picrites suggest derivation from a source of primitive mantle affinity. However, despite bulkroch geochemical indicators for a peridotite source lithology, olivine trace elements ratios suggest a minor contribution from pyroxenitic material in the source, representing possible recycling of oceanic crust into the mantle.

New $\mathrm{O}$ isotope data have been acquired on the NordSIM Cameca IMS 1280 ion microprobe for 4 samples with olivine varying from $\mathrm{Fo}_{80}$ to $\mathrm{Fo}_{89}$. Two samples with the largest range of olivine Fo exhibit relatively homogeneous $\delta^{18} \mathrm{O}$ of $\sim 6.5 \%$. In contrast, samples with the most forsteritic olivine (including the sample inferred to most closely represent the parental magma) have heterogenous $\delta^{18} \mathrm{O}$ compositions spanning the range 5.0-6.5\%. These data suggest contributions from two mantle sources in the genesis of the the Luenha picrites; one shows affinity to primitive mantle peridotite and the other has elevated $\delta^{18} \mathrm{O}$ consistent with the involvement of recycled altered oceanic crust. Thus, as for the high-Ti group, recycling of crust into the mantle appears important in the origin of the low-Ti rocks of the Karoo LIP. 